\title{
The Concept of a Regional Maintenance Center
}

\author{
Mario G. Beruvides, James L. Simonton, Natalie M. Waters, Ean Ng, \\ Siva Chaivichitmalakul, Cheng-Chu Chiu-Wei, Pelin Z. Altintas, and Phil Nash \\ Texas Tech University \\ Luis Barroso, Instituto Tecnológico de Monterrey-San Luis Potosí \\ Paul Moon, Texas Department of Transportation
}

\begin{abstract}
Key contributors to address maintenance concerns for rural transit systems are an aging fleet, poor maintenance practices, and a lack of technical expertise. This lack of local maintenance expertise is especially severe in rural areas. This paper examines the general requirements and maintenance service approach for a Regional Maintenance Center model in rural transportation systems. Among other findings of this study, it was determined that Regional Maintenance Centers, with a training center for mechanics and drivers, could improve vehicle reliability, increase vehicle longevity, and improve service to transit clientele. Also determined was that a generalized "onesize-fits-all" regional maintenance program could actually be counter-productive. Regional Maintenance Centers must be designed and located so potential use by rural transit service providers is maximized in order to provide superior serviceability and quality customer service.
\end{abstract}

\section{Introduction}

This article starts with a brief literature review of public transportation in rural areas and continues with current approaches to rural transit vehicle maintenance. 
The State of Illinois Regional Maintenance Center (RMC) model describes and illustrates a practical application of the RMC concept. Finally, the Regional Maintenance Center model is detailed with recommendations on minimum specifications, requirements, and service features, along with conclusions. The major benefit of this work is to provide an actual framework for creating an RMC and increase the base knowledge of rural transportation maintenance issues.

\section{Public Transportation in Rural America}

Transportation services for rural areas are composed of varying programs such as rural transit, elderly and disabled special services, human services, and intercity bus and rail that service rural passengers. In rural counties across the nation, there is an approximate 50 percent availability of public transit, which totals about 1,200 systems (Stommes and Brown 2002). These federally-funded transit systems commonly fall under Section 5310 (Elderly and Disabled Programs), Section 5311 (Rural Areas Program), and Rural Transportation Assistance Program (RTAP) (Federal Transit Administration 2007).

The State of Texas has a population of approximately 23 million people and is expecting a 64 percent increase over the next 25 years (Heiligenstein et al. 2006). Two goals of the Strategic Plan for 2007-2011 for Texas Department of Transportation (TXDOT) are to reduce congestion and increase transportation asset values (Heiligenstein et al. 2006). Accomplishment of these goals is connected to TxDOT strategies to empower local and regional leaders to resolve their respective transportation problems. The majority of Texas population is concentrated in metropolitan areas such as Austin, Houston, Dallas-Fort Worth, and San Antonio. This leaves a vast number of rural areas in the state where the remaining 17 percent of the population lives. Many of these rural transit systems operate in remote areas with difficult road conditions. Long travel times between destinations and poor transit conditions create an additional burden on these vehicles and organizations. Vehicles in these areas are more difficult to maintain and often need replacing more frequently than those in urban settings (Turnbull, Dresser, and Higgins 1999).

\section{Various Approaches to Vehicle Transit Maintenance}

Currently, rural transit service providers obtain maintenance for their vehicles through two major methods: in-house or third-party maintenance contracting. 
In-house maintenance performed by rural transit providers requires the service provider to maintain a technical staff that can service various vehicles types and keep an extensive and potentially expensive parts inventory. The crucial issues in maintaining a successful in-house maintenance program are a good inventory control system, determining the optimal location and design, shaping operating procedures for the maintenance facility, and the realization that maintenance is more than reorganizing or good housekeeping.

Rural transit providers can seek third-party maintenance contracting through approved and selected DOT contractors. The key to success in contracting maintenance to service providers depends mainly on the selection of contractors approved by a particular state DOT. When a state DOT has numerous maintenance contractors, difficulties arise in tracking cost and determining overall effectiveness of the maintenance provided. A rural transit provider may have to rely on local garages or local dealerships for its maintenance needs. This practice may expose it to untimely repairs, faulty workmanship, and inflated repair costs, all of which can lead to disrupted service if an alternate (loaner) vehicle is not available. Due to this lack of maintenance expertise, and regardless of maintenance method (i.e., third-party, local garage, etc.), other issues affect rural transit maintenance services, such as specialized equipment (e.g., wheelchair lifts), alternative fuel vehicle servicing, and warranty recovery being serviced in a timely manner.

A central or regionalized approach to maintenance would greatly improve overall maintenance for rural transit providers and their vehicle fleets. However, regional maintenance programs have to be developed so they are location specific and have the capacity to support servicing multiple vehicle types. A generalized "onesize-fits-all" regional maintenance program could actually be counter-productive to servicing rural transit providers because of varying factors. It is important to locate a regional maintenance center so the most natural pairing of its closest clients enables the maximum number of rural transit providers to become its potential beneficiaries. The vehicle type, model, age, and environment (climatic and economic) in which that vehicle is used are all factors needed in determining the type and frequency of prescribed maintenance. An RMC would act as a central location with full-time technical expertise to handle varied maintenance repairs efficiently and possibly at fixed costs, thus reducing overall costs for individual rural transit providers.

In an effort to examine the significance of maintenance cost in developing an effective maintenance program, Purdy and Weigmann (1987) studied 68 California 
transit agencies on the cost elements that contributed to the total cost of vehicle maintenance. They found that transit agencies with fewer than 100 vehicles had maintenance costs amounting to 15-20 percent of the agency's total budget, while the maintenance cost for agencies with more than 100 vehicles was approximately 20-30 percent of the total budget. The five main elements in maintenance cost are direct labor, maintenance administration, material and supplies, fringe benefits, and maintenance overhead. It would first appear that an agency with less than 100 vehicles has a lower maintenance cost than those with over 100 vehicles. This is somewhat misleading when considering that the increments in scaling were too wide to make an accurate determination. It would have been interesting to see the same data in 50-vehicle increments so the economies of scale could be examined. This would be important information in determining the number of vehicles required for the lowest overall associated cost. The Purdy and Wiegmann study highlights the importance of such economies of scale factors.

\section{Illinois Regional Maintenance Centers}

Our research revealed that the State of Illinois has, for several years, successfully operated an RMC model that services its rural transit providers. This example highlights the major points of Illinois' RMC model: commitment to the client, partnership with urban system, RMC locations, background reasons, vehicle loan program, and educational features.

The State of Illinois currently has three RMCs that service rural transit vehicles purchased through Illinois Department of Transportation (IDOT) funds. In addition, IDOT focuses on the welfare of the client and allows its RMCs to service non-profit Illinois agencies (nursing homes, hospitals, etc.) with transit vehicles. The IDOT Division of Public Transportation and its urban system, Illinois Mass Transit Systems, have a formal partnership that incorporated the RMCs into the mass transit systems. A formal Memorandum of Understanding (MOU) between these two parties ensures that financial concerns are separate and customer service agreements are met (Rural Transit Assistance Center 2006).

Presently, IDOT's RMCs are located in Springfield, Rockford, and Danville. These RMC facilities became official transit vehicle regional maintenance centers in 2001 for Springfield and Rockford and 2004 for Danville. According to the Rural Transit Assistance Center (2006) annual report prepared for IDOT, the Springfield RMC was the largest facility, servicing 41 agencies; the Rockford RMC serviced 
19 agencies; and the Danville RMC serviced 4 agencies. The number of agencies served by IDOT's RMCs has increased from 35 in fiscal year 2003 to 64 in fiscal year 2006. Data for fiscal years 2001 and 2002 were unavailable. All agencies must be registered with the State before any repair and maintenance scheduling occurs with any RMC. The RMCs are located such that most transit agencies are within a 60-mile radius (one-hour drive) for travel to their closest naturally-paired RMC.

According to David Spacek, IDOT's Division of Public and Intermodal Transportation Bureau Chief, the following were primary reasons IDOT moved toward a regional concept to service its transit vehicles:

- Funds were being poorly spent on maintenance repairs because vendors were not repairing vehicles correctly.

- Warranty repairs were not being honored.

- Vehicle maintenance issues/concerns needed to be identified sooner.

- There was a lack of standardization and accountability.

IDOT undertook the RMC initiative after conducting field visits throughout the state and recognizing recurring trends.

For Illinois, the main purpose for RMCs is to perform non-routine maintenance and repairs and not to compete with local garages or vendors. According to Mr. Spacek, an added benefit to IDOT RMCs is that work is completed by mechanics already knowledgeable through experience in Illinois' urban mass transit system. Because each RMC completed the process to become a warranty center, IDOT's RMCs are recognized as such and receive authorized parts and labor rates.

Additionally, IDOT RMCs have a loaner vehicle program that is available to Stateregistered agencies that participate. In the past, transit agencies with an outof-service vehicle often did not have an extra vehicle to use; thus, clients waited until the transit vehicle was repaired. The loaner vehicle is a 14-passenger van equipped with a wheelchair lift and does not require a commercial driver's license (CDL) for operation (Rural Transit Assistance Center 2006). If required, the loaner vehicle is allocated when the agency schedules a repair or maintenance through an RMC scheduler. The loaner vehicle is available to all IDOT agencies within the designated 60-mile radius and is serviced on a first-come-first-served basis. If any damage is incurred to the loaner vehicle, the borrowing agency is responsible for repairing those damages. The borrowing agency is also responsible for fuel consumed during the loan period. 
All transit vehicles using State funds are centrally procured through IDOT Division of Public Transportation. Registered agencies apply for vehicles, and IDOT develops the technical specifications, negotiates with suppliers, purchases desired equipment, and informs agencies of equipment delivery. The IDOT Division of Public Transportation hosts bi-annual training seminars named "Round Tables" for mechanics, IDOT transit representatives, and transit providers. IDOT decision making representatives (executives, maintenance managers, etc.) are important participants in these "Round Tables" because they gain a deeper understanding of critical technical issues and concerns the mechanics and transit operators are addressing and trying to resolve. By actively attending and participating, IDOT decision makers can greatly assist in the resolution of mechanical issues and concerns due to their authoritative role.

\section{Regional Maintenance Center Model}

Specifications for a public transportation regional maintenance facility are crucial in ensuring that regional transportation maintenance facilities operate in a similar manner and enable rural transit agencies to reap the maximum benefit of using an RMC. Researchers for this project reviewed the websites of all 50 state Departments of Transportation, related transportation agencies, and associated organizations, reviewed more than 100 publications, visited several private entities, and conducted observational interviews to gain a thorough baseline understanding of the state of rural transportation in general and address several critical topics. However, this paper is limited to information specifically relevant to the development and operation of an RMC.

The following specifications are a conglomeration of reviewed materials and researcher expertise and are the proposed minimum essential requirements for a regional transportation maintenance facility. These specifications are thorough but not exhaustive and cover a general definition, location specifications, building and service requirements, and other general requirements.

\section{General Definition of a Regional Maintenance Center}

An RMC is defined as a centralized public transportation maintenance facility that provides general maintenance and services to rural transit providers, as indicated in Table 1. 


\section{Table 1. General Description of a RMC}

- Provides preventive maintenance (PM), preventive inspection, major components repair, and replacement services to rural transit agencies within a given service area, county, and/or maintenance district.

- Provides maintenance and repair services beyond the scope that a local garage would provide.

- Provides services to specialized transit vehicles and equipment, including but not limited to wheelchair lifts and electric, propane and hybrid vehicles.

- Serves as a technical information center and provides technical expertise to rural transit agencies, other transit providers, and private maintenance contractors.

- Acts as warranty recovery center for all parts and labor and possibly as a designated warranty center to work on authorized original equipment manufacturing (OEM) parts.

- Provides loaner vehicles to rural transit agencies if necessary.

\section{Regional Maintenance Center Location}

A critical factor to the success of a regional maintenance center is the strategic location of the RMC as it relates to its potential rural transit providers, as indicated in Table 2.

\section{Table 2. Considerations for RMC Location}

- Most rural transit would travel routine routes in close proximity to the RMC on a regular basis to facilitate vehicle repair and maintenance.

- Maximize number of rural transit agencies that could utilize and benefit from the facility.

- Minimize overlap in coverage area by each RMC.

- Maximize market and population service.

\section{Building Requirements}

The building for a RMC may be a newly-constructed facility or a retrofitted facility, but the building requirements for such a facility should adhere to all lawful codes, address security concerns, and have enough operational capacity for vehicle maintenance and parking (Maintenance Design Group 2007). Each of these requirements is discussed briefly in Table 3. 


\section{Table 3. Considerations for RMC Building Requirements}

\section{BUILDING CODE}

All RMC facilities must comply with local, state, and federal building codes including but not limited to fire safety, structural safety, and health requirements.

\section{SITE SECURITY}

Maintenance facilities should uphold, at minimum, basic site security including but not limited to visitor sign in, camera surveillance, and secured parking for vehicles that require overnight service.

\section{PHYSICAL SPECIFICATION}

Square footage, number of bays, washing bays, and types of building should be determined by each regional RMC location and the number of rural transit vehicles serviced by the RMC. An RMC should provide a lobby or waiting area for rural transit vehicle operators waiting for vehicle maintenance.

\section{Service Requirements}

The various types of services an RMC can conduct on rural transit vehicles may range from inspections to towing services. Information on preventive maintenance, inspections, repairs, warranty services, road calls, wrecker, and loaner services is presented in Table 4. Further details on these services can be found in "TxDOT Maintenance Management and Safety Guide" (Texas Department of Transportation 2003), Schiavone (2007), and "Handbook for Rural Transit Providers" (Kansas University Transportation Center 1997).

\section{Table 4. Typical Service Types of a RMC}

\section{PREVENTIVE MAINTENANCE (PM)}

RMC should provide PM to rural transit vehicle when requested. PM procedure should comply with federal, state, local guidelines, and vehicle manufacture specifications.

\section{PREVENTIVE MAINTENANCE (PM) INSPECTION}

PM inspection on all components of a vehicle should be performed on each rural transit vehicle once it has been brought in for maintenance and repair and again before returning it to its corresponding transit agency. PM inspection should comply with federal, state, and local guidelines. An RMC should inform the corresponding agency of any wear and tear, defective or broken parts that require attention noted during the inspection and potentially set an appointment to resolve the noted problem.

\section{SAFETY INSPECTION}

In addition to safety Inspections specified by federal, state, and local guidelines, an RMC should inspect auxiliary equipment to ensure that all equipment is in working condition. Auxiliary equipment on all vehicles serviced should be inspected, including fire extinguishers, seat belts, wheelchair restraint belts, overhead compartments, etc.

\section{REPAIR SERVICES}

All services performed by RMCs should comply with the original equipment manufacturer (OEM) and any other manufacturer specifications. Repair and maintenance services an RMC should provide include but are not limited to:

- Drive Train 
- Engine services, including but not limited to major services such as repair and replace engine, replace water pumps, and minor services such as filters and fluid change.

- Transmission services, including but not limited to routine checks on existing components, service on transmission, replacing worn and broken parts, and replacing transmission with refurbished or new system.

- Differential services, usually performed in conjunction with brake service, including service, repair, and replacement of component parts as required.

- Diagnostic services, including but not limited to emission testing, transmission electronic code checks, and engine diagnostic.

- Brake services, including but not limited to pad replacement, turning or replacing brake drum, inspection and testing of pneumatic or hydraulic systems.

- Tire-related repair, including but not limited to repairing punctures, tire balancing, and tire replacement.

- Alignment and suspension services, including but not limited to replacement of worn or broken suspension part, inspection of all steering assemblies, front-end alignment, replacement and repair of worn or broken parts.

- Vehicle air conditioning system, including servicing and replacing damaged and worn components.

- Special equipment services, including but not limited to servicing and testing various types of wheelchair lifts and servicing propane, electric and hybrid vehicles.

\section{WARRANTY RECOVERY SERVICE}

An RMC should recover the warranty on all defective parts on behalf of rural transit agencies. The RMC should strive to be the designated warranty center, i.e., authorized by vehicle manufacturers to repair and replace faulty parts using original parts and authorized labor rates.

\section{ROAD CALL SERVICES}

An RMC should have a minimum of one road-call vehicle in the facility to dispatch when a vehicle breaks down.

An RMC should establish an operating procedure for using a road-call vehicle, addressing the responsibilities of the RMC and rural transit agencies when using a road-call vehicle, risk and cost sharing.

The mechanic dispatched should be able to diagnose the cause of breakdown and assess the situation. Depending on the severity of the breakdown, the mechanic should:

- Perform the repair if the repair job requires less than 30 minutes.

- Dispatch for a replacement vehicle and a wrecker vehicle if the repair requires more than 30 minutes.

\section{WRECKER SERVICES}

An RMC should establish an operating procedure that includes but is not limited to conditions to use a wrecker, a procedure to use a wrecker, and detailed responsibilities of each party involved when using a wrecker vehicle. If an RMC does not own a wrecker, the RMC should sub-contract towing services to local towing/wrecker service provider at the lowest rate possible.

\section{LOANER VEHICLE SERVICE}

Depending on the geographical location and services provided, an RMC should provide loaner vehicles to rural transit agencies on a limited basis when the rural transit vehicle requires a prolonged time period for repair. The RMC and funding entity should decide if a loaner vehicle program is needed and establish a program. This program should include but is not limited to operating procedures, conditions when a loaner vehicle is required, any charge(s) imposed on rural transit agencies for the loaner vehicle, certification required to operate a loaner vehicle, responsibilities of the RMC and the rural transit agencies on the loaner vehicle, and risk and cost sharing pertinent to the loaner vehicle. 


\section{General Requirements}

The general requirements for a RMC should cover safety concerns for the facility, employees, equipment, and maintenance training for technological advances. These factors are presented in Table 5.

\section{Table 5. General Requirements of an RMC}

\section{WORKPLACE SAFETY}

An RMC should comply with all OSHA rules and regulations pertinent to a vehicle maintenance facility. A comprehensive safety and health program should be recognized, implemented, and enforced in the maintenance workplace to prevent accidents where possible.

\section{EQUIPMENT}

An RMC should have equipment that can support the services listed in "Service Requirements."

\section{COMPUTER SOFTWARE}

An RMC should have computer software that enables it to:

- Record the details of rural transit agencies of that particular RMC, including but not limited to the number of rural transit vehicles owned by each agency, the age of each vehicle, the history of maintenance and repair on each vehicle, and the next date for preventive maintenance.

- Classify detailed documentation on each maintenance and repair activity per vehicle.

- Track the warranty recovery process.

- Track inventory, including but not limited to parts, vehicles, equipment, and machinery.

- Schedule and track the work orders within the RMC.

\section{PERSONNEL}

An RMC should maintain adequate technical and administrative personnel to cover technical assistance questions and answers for rural transit agencies or other transit providers, perform routine and non-routine maintenance and repair, ensure efficiencies in handling a vehicle loaner program, provide road call assistance, conduct warranty tracking and processing, and provide wrecker services.

\section{MECHANICS}

Classification: Mechanics should be classified based on skill level, years of experience, and demonstrated competence.

Certification: Mechanics that operate special machinery or perform maintenance and repair of special equipment should obtain proper certifications pertinent to the work performed.

\section{TRAINING}

Proper training should be provided to all mechanics prior to operating any machinery and repairing and performing maintenance on vehicles. Mechanic training on maintenance should comply with federal, state, and local guidelines/regulations.

Training should be provided to transit operators and their drivers on safety, equipment preservation, and RMC general operations.

An RMC should conduct quarterly or bi-annual maintenance roundtable sessions to keep mechanics and decision-makers abreast of issues related to transit vehicle maintenance.

- Discussion topics should include frequently-encountered problems in maintenance and repairs, latest technologies and techniques in maintenance and repairs, and benefits of PM. 
- Special issues, events, and governmental policy changes could be addressed during roundtable sessions. This includes inviting a guest speaker from the state DOT, etc.

- The typical duration of roundtable session is half day to full day.

- Attendance of all mechanics and directors of rural transit agencies (decision makers) should be mandatory.

\section{Conclusions}

The utilization of the Regional Maintenance Center concept offers many advantages over traditional in-house and third-party contracted maintenance. The opportunity to improve maintenance and increase equipment longevity while controlling cost is a very attractive undertaking. It is also important to note that each RMC should be location-specific (natural pairing with local area rural transit service providers). A "one-size-fits-all" approach is not a successful approach. Influential factors such as vehicle type, fleet age, RMC maintenance capacity, and human resource availability are very important. To service rural transit vehicles, there is an expected added cost due to possibly adding mechanics, staff, inventory parts, and specialized equipment. This added cost can be offset by a better utilization of physical and human assets. In addition, it is expected that a synergistic effect will be generated by an RMC that is related to training and dissemination of information. A centralized location such as an RMC can be used to offer specific training and certifications for transit operators and their personnel. The problems identified relate mainly to determining where to locate an RMC and what services to offer. The major benefit of this work has been increasing the base knowledge of rural transportation and providing a schema for a Regional Maintenance Center model.

\section{Acknowledgment}

Results conveyed in this paper were sponsored by Texas Department of Transportation Public Transportation Division Interagency Cooperation Contract \# 51-7XXIA006 and partially funded through Rural Technical Assistance Program (RTAP) with Federal Transit Administration funds. Professors and graduate students at the Texas Tech University Department of Industrial Engineering and a senior researcher from the Texas Tech Center for Multidisciplinary Research in Transportation (TechMRT) have completed this paper in cooperation with the Public Transportation Division of the Texas Department of Transportation. All 
opinions, errors, omissions, and recommendations are the responsibility of the authors.

\section{References}

Federal Transit Administration. 2007. Grant Programs. FTA website, http://www. fta.dot.gov/funding/grants_financing_263.html, accessed May 10, 2007.

Heiligenstein, M., J. Albert, R. Davenport, N. Perales, H. Andrade, and G. Pate 2006. TxDOT has a plan: Strategic plan for 2007-2011. Texas Department of Transportation, TxDOT Strategic Plan 2007-2011, ftp://ftp.dot.state.tx.us/pub/ txdot-info/lao/strategic_plan2007.pdf, accessed May 1, 2007.

Kansas University Transportation Center. 1997. Handbook for rural transit providers transit vehicle inspections: Delivery, pre-trip and annual inspection procedures. http://www.cutr.usf.edu/bussafety/documents/tvi-handbook. pdf, accessed June 20, 2007.

Maintenance Design Group. 2007. http://www.maintenancedesigngroup.com/, accessed July 17, 2007.

Purdy, J.E., and J.D. Wiegmann. 1987. Vehicle maintenance: Cost relationship and estimating methodology. Transportation Research Record: Journal of the Transportation Research Board 1140: 1-17.

Rural Transit Assistance Center. 2006. Annual report: Illinois Regional Maintenance Center fiscal 2006 assessment. Western Illinois University.

Schiavone, J. 1997. Synthesis of transit practice 22: Monitoring bus maintenance performance (TCRP Synthesis 22). Guilford: Federal Transit Administration, Transit Development Corporation.

Stommes, E.S., and D.M. Brown. 2002. Transportation in rural America: Issues for the 21st century. Rural America 16(4): 10.

Turnbull, K.F., G.B. Dresser, and L.L. Higgins. 1999. The rural transportation network in Texas (No. FHWA/TX-99/1437-1), Texas Department of Transportation.

Texas Department of Transportation, Public Transportation Division. 2003. TxDOT maintenance management and safety guide. http://www.dot.state.tx.us/publications/public_transportation/mgmtguide.pdf, accessed June 20, 2007. 


\section{About the Authors}

NATALIE M. WATERS (natalie.waters@ttu.edu) received an M.S. degree in Industrial Engineering from the University of Texas at El Paso and a B.A. degree in Psychology from New Mexico State University. Currently, she is a Research Assistant at Texas Tech University pursuing her doctorate in Industrial Engineering. Previously, she worked for Levi Strauss and Company in its manufacturing and distribution/logistics divisions as an industrial engineer, shift manager, project manager, and operations manager. Her research interests are focused on knowledge workers, teams, knowledge management, and engineering management.

MARIO G. Beruvides, PhD., P.E. (mario.beruvides@ttu.edu) is the AT\&T professor in the Industrial Engineering Department at Texas Tech University and Director of the Laboratory for Systems Solutions. He received his Ph.D. from Virginia Polytechnic Institute \& State University. His major areas of interest are advanced economic analysis, management of technology, engineering management, whitecollar/knowledge work, productivity and performance measurement, operations and systems engineering, and macro-ergonomics.

JAMES L. Simonton, PhD., P.E. (james.simonton@ttu.edu) received his Ph.D. from Texas Tech University in Industrial Engineering. He holds an M.S. degree in Systems and Engineering Management from Texas Tech University and a B.S. degree in Textiles from Texas Tech University and is a professional engineer in the state of Texas. $\mathrm{He}$ is an Assistant Professor of Industrial Engineering at Texas Tech University. His research interests include operational research, engineering economics, logistics, and quality. He worked for 20 years in the manufacturing industry prior to his academic career.

EAN-HARN NG, E.I.T. (ean.ng@ttu.edu) is a Ph.D. student in System and Engineering Management from Texas Tech University. She holds an M.S. degree in Industrial Engineering from Texas Tech University and a B.S. degree in Industrial and Management Engineering from Montana State University. Her research interests include engineering economic, engineering management, engineering education, and organization behavior.

Siva ChaivichitmalaKUL (siva.chaivichitmalakul@ttu.edu) is a Ph.D. student in System and Engineering Management from Texas Tech University. He holds a B.S. degree in Civil Engineering from Sirindhorn International Institute of Technology, Thammasat University, Thailand. His research interests are biomass fuels, alternative fuels, economic modeling and engineering economic. 
Cheng-Chu ChiU-Wei (cc.chui-wei@ttu.edu) is a research assistant of Industrial Engineering at Texas Tech University. He received an M.S. in Engineering Management from Southern Methodist University and a B.A. in Industrial Management from Chung Hua University. His research interests include engineering management, production engineering, and systems solutions.

Pelin Z. Altintas (pelin.z.altintas@ttu.edu) is a Ph.D. student in the Industrial Engineering Department of Texas Tech University where she received M.S. and B.S. degrees in Industrial Engineering. Her research interests are cost of quality, systems and engineering management, and operation research.

LUIS A. BARRoso, Ph.D. (luis.barroso@itesm.mx) is a professor at the Instituto Tecnológico de Monterrey-San Luis Potosí, in México. He received his Ph.D. from Texas Tech University in Systems and Engineering Management and holds an M.S. in Systems and Engineering Management and a B.S. in Computer Science from Universidad de las Américas in Puebla, México. His research interests include engineering economic, systems theory, community development, and systems improvement

Phillip T. NASH, P.E. (Phil.Nash@ttu.edu) received M.S. and B.S. degrees in Civil Engineering from Texas Tech University. He currently serves as Director of the Texas Tech Center for Multidisciplinary Research in Transportation. He has more than 20 years of experience in a broad spectrum of transportation research including vehicle crash studies, development of expedient repair techniques for damaged pavements, evaluation of cathodic protection systems to mitigate corrosion of reinforced concrete bridge elements, wind and traffic loadings on highway bridges, development of environmental specifications for roadway construction materials, the use of recycled materials in roadway construction, evaluation of military deployment routes throughout Texas, and rapid replacement of bridges damaged by extreme events.

PAUL Moon (pmoon@dot.state.tx.us) received an M.A. in Human Services Administration from Saint Edward's University and a B.A. in Geography from the University of Texas at Austin. Previously, he served in the United States Army's Transportation Corps as a platoon leader and detachment commander in various posts in the United States, South Korea, and in the Persian Gulf, where he was awarded the Bronze Star. In his current position as fleet planner, he assists transit agencies and transit program managers with fleet management functions including procurement, maintenance, and inventory. 